International Journal of Health Sciences
Available online at www.sciencescholar.us
Vol. 6 No. 1, April 2022, pages: $115-124$
e-ISSN: 2550-696X, p-ISSN: 2550-6978
https://doi.org/10.53730/ijhs.v6n1.3420

\title{
Scientific and Communicative Interaction in HEIs during Pandemic
}

\author{
(C) CrossMark \\ Olha Rusakova a, Iryna Tamozhska ${ }^{\text {b }}$, Tetiana Tsoi c, Liudmyla Vyshotravka ${ }^{d}$, Roksolyana Shvay e \\ Manuscript submitted: 28 August 2021, Manuscript revised: 27 November 2021, Accepted for publication: 30 December 2021
}

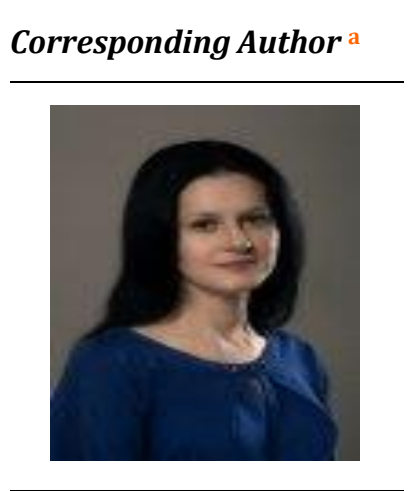

Keywords

communicative interaction, digital education; distance education; education quality; educational process; higher education; inclusive education; pandemic;

\begin{abstract}
This article aims to identify the benefits of the online platform for scientific and communicative interaction in HEIs during the pandemic. Pedagogical experiment during the academic year 2020/2021 was chosen as the main method of research, which included the study of the Mentimeter's effectiveness (online platform) and a students' survey at the Kyiv National University of Culture and Arts (KNUCaA). Results. The study showed that the use of the Mentimeter platform resources significantly increases the level of the student audience interest in the course material and during the study as a whole. This platform was involved by the teachers to work with students during the lecture or for educational purposes. Also, it was aimed to get feedback from students about the subject course content or the lecturer's methodological developments. Online surveys, created with the platform's help, allow establishing synchronous communication with the students during the lecture session remotely. Students' evaluation of the communication component of distance education under such conditions has higher rates. Communicative practices, which implementation into educational process contributes to the formation of open, communicative educational environment in modern institution of higher education, under long-distance education are of great importance not only for learning.
\end{abstract}

International Journal of Health Sciences (C) 2022. This is an open access article under the CC BY-NC-ND license (https://creativecommons.org/licenses/by-nc-nd/4.0/).

\section{Contents}

Abstract.

1 Introduction.

\footnotetext{
a Vasyl Stefanyk Precarpathian National University, Ivano-frankivsk, Ukraine

${ }^{\text {b }}$ V. N. Karazin Kharkiv National University, Kharkiv, Ukraine

c National Academy of Fine Arts and Architecture, Kyiv, Ukraine

${ }^{\text {d }}$ Kyiv National University of Culture and Arts, Kyiv, Ukraine

e Lviv Polytechnic National University, Lviv, Ukraine
} 


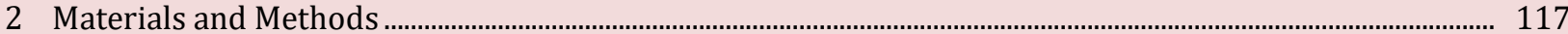

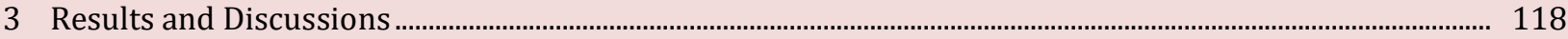

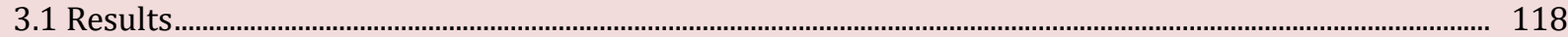

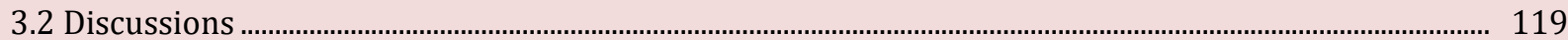

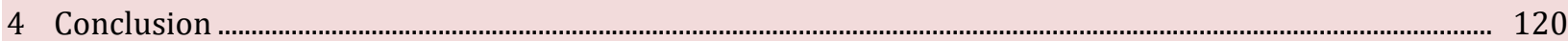

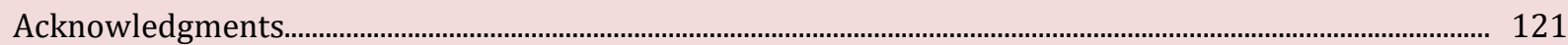

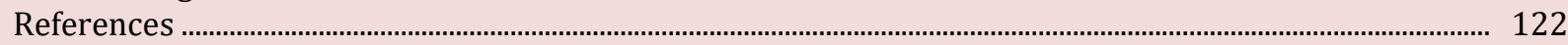

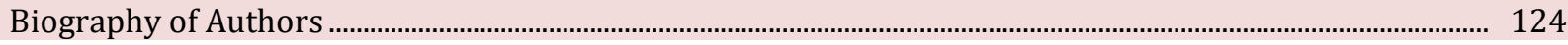

\section{Introduction}

The communicative component of the educational process has a special value for the competencies related to the application of human communication skills. The challenges that humanity has faced with the COVID-19 pandemic in many areas of culture, particularly in education, have prompted the search for new forms of interaction. The education transition to the online format has posed many serious challenges to the educational process participants (Campbell, 2020; Clase et al., 2020). It is aimed at solving the key question of the distance form of education: how to organize the educational process in such a way as to preserve the educational services' cornerstone - the teacher-student communication. Such interaction both provides an appropriate level of knowledge transfer that corresponds to the subject content of the disciplines and can be monitored by the teacher for its scientific and curriculum compliance and also allows establishing (maintaining) contact between a teacher and a student. It is important not only for quality learning but also for the personal formation of a young person, for overcoming psychological and pedagogical tension, which accompanies both the learning process, which in institutions of higher education is not only a problem but also the main factor in the education quality (Van Dinther et al., 2011; Mishra et al., 2020; Graham et al., 2013).

The search for opportunities for such interaction began to actively take place thanks to an online platforms' variety, both those that were already partially involved in the educational process and those that began to offer new services (Chandna \& Salimath, 2018; Casais et al., 2020; Van Noort \& Willemsen, 2012). The experience gained by HEIs under such circumstances showed the presence of effective mechanisms of communication between teachers and students and the possibility in the conditions of distance education to mobilize the educational process in the direction of providing quality educational services, creating favorable conditions for harmonious personal development and overcoming the social and psychological challenges of time. The article aims to identify the advantages of online platforms to ensure scientific and communicative interaction in HEIs during the pandemic (Bejarano et al., 1997; Pamplona et al., 2001).

\section{Literature review}

The academic literature notes the importance of building teachers' digital culture to enhance the communicative interaction effects and implementation of digital educational technologies (Kohnke, 2019; Mayhew, 2019; Bertolini et al., 2019; Smagulova et al., 2020). Several studies have described the use of the online platform Mentimeter. Such systems provide students with a flexible and varied way to respond via mobile devices. Student response systems (SRS) include Mentimeter, Kahoot, Plickers, GoSoapBox, and Poll Everywhere (Moorhouse \& Kohnke, 2020). Because of its versatility and unlimited participants number, Mentimeter has greater potential for use in HEIs to provide communication interactions.

The platform's impact on student learning has been investigated by English researchers Mayhew et al. (2020). The use of Mentimeter in English language teaching has been described by Moorhouse \& Kohnke (2020). Among the studies, there have been many analyses of the platform's effectiveness over the past 20202021 (Pichardo et al., 2021; Mohin et al., 2020; Hill, 2020; Gokbulut, 2020). Mentimeter is a web-based Clicker, Audience Response System (ARS) or Student Response System (SRS) that allows students to respond to digital questions using a mobile device. The platform has the potential to transform the educational environment into a more interactive, engaging, and inclusive one (Mohin et al., 2020). Mentimeter has thirty million users all around the world (Mentimeter, 2019) and combines quiz, polling, and presentation digital instruments. Mentimeter offers free, basic, and pro price plans for teachers and educational basic and 
educational pro for academics. In this study, the focus is on a free plan for large lectures with unlimited participants numbers. The use of up to two main questions different types and four quizzes per presentation in the free plan is sufficient for a two-hour lecture. Otherwise, Trees \& Jackson (2007), prove the low level of student satisfaction with using Mentimeter.

Researches show that a proactive discussion dialogic approach to learning is sufficient than passive teaching practice. Students' participation can be encouraged by using a simple accessible audience response program that allows for inclusive and instant communication between personnel and students in classrooms (Mayhew et al., 2020; Ernawati et al., 2022).

Easy setup involves going to https://www.mentimeter.com and creating an account, adding slides, and then choosing from Quick Slide for presentation type, question type, or quiz slides. The range of question type formats includes the Image Choice, Multiple Choice, 2 by 2 Matrix, and Q\&A. Slides present independently online or via a plug-in that download through Office365. Once completed, a QR code is generated or students can go to https://www.menti.com and enter the six-digit code using mobile devices. The Mentimeter is set to dictate by the students or instructor. Then the students read the question, agree on the answer, the result of which the scientist can decide whether to show the students (Hill, 2020).

The Mentimeter software both stimulates student participation during the COVID-19 (both online and face-to-face) synchronously and asynchronously and improved engagement, attention, interaction, and collaboration during learning practice (Martyniv et al., 2021). Instant feedback allows teachers to monitor student results learning and change material and content. Students and teachers highlighted the tool inclusive potential as it allows for participation from different audiences with different abilities and backgrounds, ensuring an equitable and inclusive education for all. Some room for improvement was also identified, namely additional features to make the software more attractive and to adapt it to different educational purposes (Pichardo et al., 2021; Hepsiba et al., 2018).

Mentimeter is used in the educational process of different students' specialties. Case studies from 20202021 indicate that educators are searching for new forms of communication with student audiences during instruction in the COVID-19 pandemic era and that there is a growing interest in analyzing existing experiences (Diachenko et al., 2021). Such an incomplete but representative list of scientific sources of recent years demonstrates the necessity of modern education processes of digitalization and gamification, the importance of popularizing among the academic community analysis of specific experiences of using digital platforms in the educational process to improve them and implement them as widely as possible.

\section{Materials and Methods}

During the 2020/2021 academic year, teachers from the Department of Philosophy and Pedagogy at Kyiv National University of Culture and Arts (KNUCaA) conducted a pedagogical experiment that consisted of studying the effectiveness of introducing Menti-survey to the teaching of the "Philosophy" course of students from different faculties of the university. The lectures, given by teachers in an online format, were accompanied by presentations created in PowerPoint and Keynote programs. The following steps were taken to attach Menti-survey to the existing presentation:

- A survey was created on the Mentimeter platform. Its model can be chosen by the teacher depending on the purpose of the survey. Therefore, surveys can have instructional, control, and assessment purposes. A questionnaire or test of an instructional nature requires further commentary by the teacher, identifying and explaining correct and incorrect positions. Surveys designed to control knowledge show the level of knowledge absorbed during the lecture. Evaluation polls help to find out the accessibility of the lecture material, the clarity of the lecturer's explanations, interest in the topic, and other issues. Possibilities provided by the platform, combined with the imagination and creativity of the teacher, allow to realize an infinite number of different tasks and get diverse information about the group of listeners, the knowledge they received, the lecture they visited.

- Formed a way of distributing the menti-survey to the participants. To do this, one of three options was used: 1) generating a QR-code, 2) creating a link that took the student directly to the survey, and 3)

Rusakova, O., Tamozhska, I., Tsoi, T., Vyshotravka, L., \& Shvay, R. (2022). Scientific and communicative interaction in HEIs during pandemic. International Journal of Health Sciences, 6(1), 115-124. https://doi.org/10.53730/ijhs.v6n1.3420 
creating a code that the student entered on the website: http://mentimeter.com. Each of these three paths led the student to the lecturer-created menti-survey. The platform generates the links and codes on its own. To do this, the student needs to click "Share," copy the link, code, and download the QRcode.

- Presentations, which were shown during the lectures, contained all the links with the QR-code and instructions for the survey/test. Students could read the QR-code and access the survey from the displayed slide. It was also appropriate to send pre-created menti-survey links to the chat room. The menti-survey was quite harmonious in the lectures' context, regardless of the specialization of the student audience and the lecture theme.

The following online surveys, available on the platform, were used to work with students during lectures:

- Surveys in which answer options are offered (as a test). Visually the results of such a survey may have a different appearance. The survey's author can select the option of the visual design of the results at his discretion.

- Surveys where participants can enter their answers. An example of this type of training survey is the "cloud" formation, in which the most commonly used concepts are displayed in large font.

- Surveys where participants establish a measure of agreement or disagreement with certain statements (Fig. 3, 4). This survey allows teachers to see to what extent the audience has absorbed the listening material, analyze the survey results, and focus on the correct answers. Also, this type of survey allows the teacher to track what percentage of the audience perceives the lecture material appropriately and make adjustments through its delivery to improve the quality of teaching.

- Surveys allow students to evaluate the lecture material for its accessibility and determine the level of material understanding during the lecture, the teacher mastery, etc.

These surveys have an academic purpose because they require additional comments from the teacher on the answers given, do not involve identifying the student in the system when voting, and do not involve a test/questionnaire grading scale. Voting results are instantaneous, so you can get feedback and comment on it in a few minutes. Menti-surveys can be created to elicit feedback and impressions from student audiences on a wide variety of issues. The anonymity of the vote (as noted by students in their feedback in questionnaires developed by the university's student parliament) ensures honest responses and reproduction of the real picture on certain issues. Feedback can be obtained quickly, without much time or money. The conducted surveys were created on the basic version of the free platform. However, this platform resource also allowed to get interesting and useful results, which can be relevant both for the teacher reading the discipline and for the department, the dean's office, the academic department, and other participants in the educational process.

\section{Results and Discussions}

\subsection{Results}

The empirical study proves that there are no differences in the students' answers from different faculties to the same survey questions within the same experimental group. It means a well-established communication between students and the teacher, a high level of organization of the learning process, which ensured the proper level of learning material assimilation by the audience during the lectures. It should be noted that the introduction of online surveys to the lecture significantly increased the rates of student attendance of lecture classes, even if the surveys (which are voluntary) were not attended by all students present at the online lecture. The students who participated in such surveys (experimental group) had attendance rates ranging from $85-95 \%$ (203-227 students) of the total number of students in the stream (239 people), while similar rates in the control group averaged 75-85\% (108-122 students out of 144) (analyzed data on student attendance in lectures recorded by the teaching unit). It confirms the audience's interest in this form of communication with the teacher at the lecture and motivates the student to learn. The university-wide survey conducted annually by the Student Parliament to examine student feedback on the teaching process and the 
teachers, who provide it, also witnessed an increase in the rating of the teacher who worked in the experimental group (rating 8.6 out of 10 in the 2019/2020 academic year and 9.3 out of 10 in the 2020/2021 academic year), while the rating of the control group teacher was unchanged compared to his previous performance (rating 9 out of 10 during the 2019/2020 and 2020/2021 academic years).

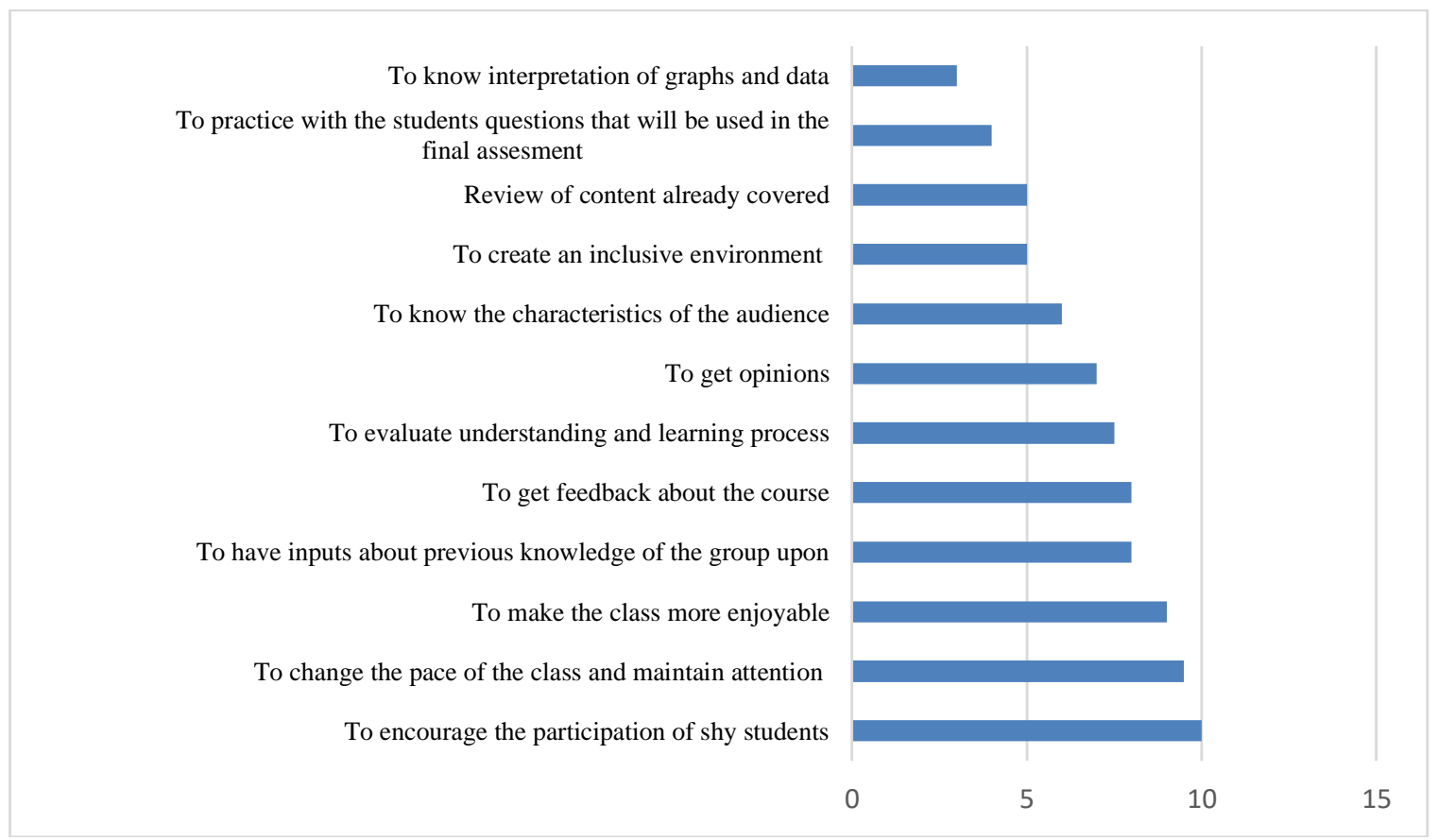

Figure 1. Rank what you consider the main reasons for using Mentimeter in class Source: author's research

It should be noted that students in both groups showed their interest in involving online platforms in the educational process. Comparison of the survey results on the communication level of the teacher with students in the conditions of distance education in the experimental and control groups is not fundamentally different, which indicates the following: the teacher can establish contact with the audience in distance education, the involvement of online platforms is an additional, but important factor in improving the communication process.

In addition to teaching and evaluation surveys, on the Mentimeter platform, you can create such types of surveys that allow students to ask questions throughout the lecture, create gamified tasks, quizzes, competitions among students. Both text surveys and images that allow you to creatively create a test can be included in such quizzes' creation. Gamified tests are perceived with particular enthusiasm by the student audience, as evidenced by the results of the authors' observation of the article during their pedagogical work. Increased student activity in lectures showed the already mentioned quiz, which teachers of the philosophy and pedagogy department organized together with the staff of the scientific library of Kyiv National University of Culture and the Arts.

Surveys created by teachers of the Kyiv National University of Culture and Arts and teachers who work with the student audience in the "Philosophy" course can be similarly used in the teaching process of other humanitarian and general education disciplines. It strengthens the didactic effect of their lecture component and contributes to bringing to the student audience the subject content of these disciplines, the content of which has a personal direction and involves discussing this content with the experience of their colleagues, as well as extrapolating the results of this discussion in a broad socio-cultural context. The emergence during the last year of a great variety of online platforms, the creation of the latest tools based on existing ones that ensure comfortable and productive work and communication online, indicates that society is working hard to create a new, comfortable online environment for learning and work. The example of the application of the

Rusakova, O., Tamozhska, I., Tsoi, T., Vyshotravka, L., \& Shvay, R. (2022). Scientific and communicative interaction in HEIs during pandemic. International Journal of Health Sciences, 6(1), 115-124. https://doi.org/10.53730/ijhs.v6n1.3420 
online platform Mentimeter in the preparation of online philosophy lectures at Kyiv National University of Culture and Arts showed that modern online programs create powerful opportunities for productive communication, satisfying the needs of the applicant for education and the teacher.

\subsection{Discussion}

This study also confirmed the pedagogical benefits of the Mentimeter online platform identified by scientists, including increased levels of communication, motivation, student engagement, obtaining opinions, and evaluating students' understanding of the teaching material. Teachers differentiate classical lectures where the educator monotonically presents the material through the questions or prompts. Quick and instant responses engage students in the material delivery and increase their interest. Quizzes and rankings are effective at increasing student engagement (Twyman \& Heward, 2018). Such features provide proper support for student interest, shaping the overall learning environment and knowledge construction through the anonymity of student responses and instant correct answers.

The platform's ease of use is ensured by the wide range of possible answer choices, a large number of formats, which allows for a quick understanding of the audience's opinion. These communicative interaction forms can be used to encourage discussion in-group (Moorhouse, 2017) through open-ended questions or word sets. Student ideas are the basis for teachers to structure lectures and classes according to identified interests to increase engagement and achieve specific pedagogical learning goals.

For example, a teacher provides students with course-specific research materials and asks them to compose a list of questions anonymously through open-ended questions that arise in the classroom during an instant preview on the platform. Such questions are important to discuss in class. Students can gain specific and specialized vocabulary within an academic discipline through a set of basic concepts. Teachers often face the challenge of assessing students' understanding of academic material due to psychological factors. Therefore, the platform can be used to identify and assess prior knowledge and audience expectations. The platform is also effective for collecting students' opinions about the learning process and collecting questions about the presentation and quality of materials (Wahab \& Tyasari, 2020).

Mentimeter is also an effective platform for students. Students can give their ideas and opinions on interesting and effective tasks. The anonymity of responses on the platform forms a safe environment to ask questions and make suggestions (e.g., how can this course better meet language-learning needs? How might the discipline be better suited to the study field?)

The above-mentioned learning strategies and tactics ensure the effectiveness of the learning process and the success of the participation in the professional academic community (Hill, 2020). However, among the limitations of the Mentimeter platform is the lack of opportunities for students to verbally express their own opinions. To address this limitation, students can be given time to discuss their responses in pairs, in groups, before expressing them on the Mentimeter platform (Moorhouse, 2017; Widana et al., 2021). Some active students, who want to verbally answer questions, need live interaction and may not be sufficiently satisfied with Mentimeter. Therefore, the teacher needs to combine different teaching methods in practice and not overuse digital tools to engage and motivate students.

\section{Conclusion}

The study demonstrated that the use of Mentimeter platform resources significantly increases the level of interest of the student audience in the course material and during the study in general. This platform was used by the teachers to work with students during a lecture or for learning purposes. It allowed teachers to get feedback from the students about the course subject content or the lecturer's methodological developments. Online surveys, which were created with the platform help, allow for synchronous communication with students during the lecture session remotely. Students' evaluation of the communication component of distance education under such conditions has higher rates. It is confirmed by the students' anonymous survey "Teacher through the eyes of students" results, which is held annually at the university. As the experience of Kyiv National University of Culture and Arts testifies, under the conditions of a pandemic caused by COVID-19, participants of the educational process as creative individuals find "proper responses" 
(as English philosopher A. J. Toynbee put it) to the urgent challenges of time. The analysis of the study experience of Kyiv National University of Culture and Arts in attracting Mentimeter platform to the formation of communicative educational environment can be used not only during the "Philosophy" course but also implemented in other education humanitarian disciplines. It can also be useful for educational process participants of other higher education institutions; its coverage and analysis should be the subject of further research. The academic community's discussion of technologies for introducing the described experience will make it possible to improve and refine the existing practices.

The subject of a separate study should be a comparative analysis of the communication resources of the Mentimeter platform and education online services offering the implementation of real-time interactive interaction in the learning process (Classtime, Kahoot, Mentimeter, Nearpod, Online Test Pad, Quizalize, Quizizz, Quizlet); study of the advantages that each of them has; analysis of the experience of the parallel use in lecture courses of different educational platforms, their choice by the teacher with the individual lecture classes and didactic goals a person sets. Communicative practices, the introduction of which in the educational process contributes to the formation of an open communicative and educational environment in a modern institution of higher education, in long-distance education are important not only for learning but also for the harmonious development of personality and overcoming social and psychological challenges of time, which should be a subject of the scientific study of subsequent research.

Acknowledgments

We are grateful to two anonymous reviewers for their valuable comments on the earlier version of this paper.

Rusakova, O., Tamozhska, I., Tsoi, T., Vyshotravka, L., \& Shvay, R. (2022). Scientific and communicative interaction in HEIs during pandemic. International Journal of Health Sciences, 6(1), 115-124. https://doi.org/10.53730/ijhs.v6n1.3420 


\section{References}

Bejarano, Y., Levine, T., Olshtain, E., \& Steiner, J. (1997). The skilled use of interaction strategies: Creating a framework for improved small-group communicative interaction in the language classroom. System, 25(2), 203-214. https://doi.org/10.1016/S0346-251X(97)00009-2

Bertolini, L., Brömmelstroet, M. T., \& Pelzer, P. (2019). If a mobility transition is what we want, transport research should.... Transportation Research Procedia, 41, 824-829.

Campbell, A. M. (2020). An increasing risk of family violence during the Covid-19 pandemic: Strengthening community collaborations to save lives.Forensic science international: reports, 2, 100089. https://doi.org/10.1016/j.fsir.2020.100089

Casais, B., Fernandes, J., \& Sarmento, M. (2020). Tourism innovation through relationship marketing and value co-creation: A study on peer-to-peer online platforms for sharing accommodation. Journal of Hospitality and Tourism Management, 42, 51-57. https://doi.org/10.1016/j.jhtm.2019.11.010

Chandna, V., \& Salimath, M. S. (2018). Peer-to-peer selling in online platforms: A salient business model for virtual entrepreneurship. Journal of Business Research, 84, 162-174. https://doi.org/10.1016/j.jbusres.2017.11.019

Clase, C. M., Fu, E. L., Ashur, A., Beale, R. C., Clase, I. A., Dolovich, M. B., ... \& Carrero, J. J. (2020). Forgotten technology in the COVID-19 pandemic. Filtration properties of cloth and cloth masks: a narrative review. In Mayo Clinic Proceedings. Elsevier. https://doi.org/10.1016/j.mayocp.2020.07.020

Diachenko, A., Vusyk, H., Bielova, Y., Shurdenko, M., \& Titenko, O. (2021). The educational role in COVID-19 terms of ethnodesign graphic function in higher education practical activities. International Journal of Health Sciences, 5(3), 584-593. https://doi.org/10.53730/ijhs.v5n3.2540

Ernawati, E., Baso, Y. S., Hidayanty, H., Syarif, S., Aminuddin, A., \& Bahar, B. (2022). The effects of anemia education using web-based she smart to improve knowledge, attitudes, and practice in adolescent girls. International Journal of Health \& Medical Sciences, 5(1), 44-49. https://doi.org/10.21744/ijhms.v5n1.1831

Gokbulut, B. (2020). The effect of Mentimeter and Kahoot applications on university students'elearning. World Journal on Educational Technology: Current Issues, 12(2), 107-116.

Graham, C. R., Woodfield, W., \& Harrison, J. B. (2013). A framework for institutional adoption and implementation of blended learning in higher education. The internet and higher education, 18, 4-14. https://doi.org/10.1016/j.iheduc.2012.09.003

Hepsiba, N., Subhashini, A., Raju, M., \& Rao, Y. P. (2018). Changing role of teachers in the present society. International Journal of Health \& Medical Sciences, 1(1), 35-38.

Hill, L. (2020). Mentimeter: A tool for actively engaging large lecture cohorts. Academy of Management Learning \& Education, 19(2), 256-258.

Kohnke, L. (2019). GoSoapBox-Encourage participation and interaction in the language classroom. RELC Journal, 0033688219872570.

Martyniv, L., Sokolova, A., Kurinna, S., Kopeliuk, O., Sediuk, I., \& Khomova, O. (2021). The modern problems and prospects of music formation and art education development during COVID-19. International Journal of Health Sciences, 5(3), 670-680. https://doi.org/10.53730/ijhs.v5n3.2936

Mayhew, E. (2019). No longer a silent partner: How Mentimeter can enhance teaching and learning within political science.

Mayhew, E., Davies, M., Millmore, A., Thompson, L., \& Pena, A. (2020). The impact of audience response platform Mentimeter on the student and staff learning experience. Research in Learning Technology, 28.

Mishra, L., Gupta, T., \& Shree, A. (2020). Online teaching-learning in higher education during lockdown period of COVID-19 pandemic. International Journal of Educational Research Open, 1, 100012. https://doi.org/10.1016/j.iheduc.2012.09.003

Mohin, M., Kunzwa, L., \& Patel, S. (2020). Using Mentimeter to enhance learning and teaching in a large class.

Moorhouse, B. (2017). Using Mentimeter for teacher training and language teaching. Modern English Teacher, 26(3), 41-43.

Moorhouse, B. L. (2017). Increasing in-class participation with online tools. The Teacher Trainer.

Moorhouse, B. L., \& Kohnke, L. (2020). Using Mentimeter to elicit student responses in the EAP/ESP classroom. RELC Journal, 51(1), 198-204. 
Pamplona, M. C., Ysunza, A., \& Jimenez-Murat, Y. (2001). Mothers of children with cleft palate undergoing speech intervention change communicative interaction. International journal of pediatric otorhinolaryngology, 59(3), 173-179. https://doi.org/10.1016/S0165-5876(01)00476-1

Pichardo, J. I., López-Medina, E. F., Mancha-Cáceres, O., González-Enríquez, I., Hernández-Melián, A., BlázquezRodríguez, M., ... \& Borrás-Gené, 0. (2021). Students and Teachers Using Mentimeter: Technological Innovation to Face the Challenges of the COVID-19 Pandemic and Post-Pandemic in Higher Education. Education Sciences, 11(11), 667.

Smagulova, B. G., Chernyshova, T. V., \& Idrissova, M. A. (2020). Students engagement in blended learning: digital educational resources as an interactive approach.

Trees, A. R., \& Jackson, M. H. (2007). The learning environment in clicker classrooms: student processes of learning and involvement in large university-level courses using student response systems. Learning, Media and Technology, 32(1), 21-40.

Twyman, J. S., \& Heward, W. L. (2018). How to improve student learning in every classroom now. International Journal of Educational Research, 87, 78-90. https://doi.org/10.1016/j.ijer.2016.05.007

Van Dinther, M., Dochy, F., \& Segers, M. (2011). Factors affecting students' self-efficacy in higher education. Educational research review, 6(2), 95-108. https://doi.org/10.1016/j.edurev.2010.10.003

Van Noort, G., \& Willemsen, L. M. (2012). Online damage control: The effects of proactive versus reactive webcare interventions in consumer-generated and brand-generated platforms. Journal of interactive marketing, 26(3), 131-140. https://doi.org/10.1016/j.intmar.2011.07.001

Wahab, A., \& Tyasari, I. (2020). Entrepreneurial leadership for university leaders: A futuristic approach for Pakistani HEIs. Asia Pacific Management Review, 25(1), 54-63. https://doi.org/10.1016/j.apmrv.2019.09.002

Widana, I.K., Sumetri, N.W., Sutapa, I.K., Suryasa, W. (2021). Anthropometric measures for better cardiovascular and musculoskeletal health. Computer Applications in Engineering Education, 29(3), 550561. https://doi.org/10.1002/cae.22202

Rusakova, O., Tamozhska, I., Tsoi, T., Vyshotravka, L., \& Shvay, R. (2022). Scientific and communicative interaction in HEIs during pandemic. International Journal of Health Sciences, 6(1), 115-124. https://doi.org/10.53730/ijhs.v6n1.3420 


\section{Biography of Authors}

\begin{tabular}{|c|c|}
\hline & $\begin{array}{l}\text { Olha Rusakova } \\
\text { PhD, Assistant Professor, Kolomyya Educational-Scientific Institute, Vasyl Stefanyk } \\
\text { Precarpathian National University } \\
\text { ORCID identifier: 0000-0002-1860-7922 } \\
\text { Email: olga.iai.rusakova@gmail.com }\end{array}$ \\
\hline & $\begin{array}{l}\text { Iryna Tamozhska } \\
\text { Doctor of Pedagogical Sciences, Associate Professor at the Department of } \\
\text { Language Training 1, Department of Language Training 1, Institute of } \\
\text { International Education for Study and Research, V. N. Karazin Kharkiv National } \\
\text { University } \\
\text { ORCID identifier: 0000-0003-0865-2380 } \\
\text { Email: itamozskaXX3@ukr.net }\end{array}$ \\
\hline & $\begin{array}{l}\text { Tetiana Tsoi } \\
\text { Ph.D. in Philosophy, Associate Professor, Department of Theory and Art History, } \\
\text { Department of Culture and Social and Humanitarian Sciences, National Academy } \\
\text { of Fine Arts and Architecture } \\
\text { ORCID identifier: 0000-0003-4413-1478 } \\
\text { Email: tatianatsoyII@gmail.com }\end{array}$ \\
\hline & $\begin{array}{l}\text { Liudmyla Vyshotravka } \\
\text { Associate professor, Kyiv National University of Culture and Arts } \\
\text { ORCID identifier: 0000-0002-7084-8571 } \\
\text { Email: vushotravkaX3Iludmula@gmail.com }\end{array}$ \\
\hline & $\begin{array}{l}\text { Roksolyana Shvay } \\
\text { Doctor of Pedagogical Sciences, Full Professor, Institute of Jurisprudence, } \\
\text { Psychology and Innovative Education, Department of Pedagogy and Innovative } \\
\text { Education, Lviv Polytechnic National University } \\
\text { ORCID identifier: 0000-0003-3859-5196 } \\
\text { Email: roksolyanashхна@yahoo.com }\end{array}$ \\
\hline
\end{tabular}

